\title{
Effectiveness of e-Learning in Public Health Education: A Pilot Study
}

\author{
Zhixia Zhang, Peng Ran, Ying Peng, Rong Hu, and Weirong Yan
}

\begin{abstract}
Medical schools educators are presently experimenting with innovative ways of using e-learning to supplement the existing teaching. E-learning can promote an active, deeper approach for learning that enhances student learning outcomes. However, little literature explores the application of e-learning into public health education. The aim is to assess the effectiveness of e-learning in public health. A descriptive study, with a total of 87 international students of the Bachelor of Medicine and Bachelor of Surgery (MBBS) enrolled, was conducted at Tongji Medical College, Huazhong University of Science \& Technology, Wuhan, China. To evaluate the effectiveness of e-learning platform, correlations between students' e-learning platform usage and the final examination marks were analyzed. The major contribution of this paper is E-learning platform usage had positive correlations with students' final examination marks. E-learning is promising and worthwhile for further application in public health education.
\end{abstract}

Index Terms-E-learning, pilot study, platform, public health.

\section{INTRODUCTION}

Public health, an important branch of medicine, refers to application of health-related strategies for disease prevention, health promotion and improvement of quality of life [1], [2]. With development of economic and change of medical model, more and more attention has been paid on the promotion of health. However, many risk factors existed threaten to people's health, for example, contamination of environment, prevalence of chronic non-communicable diseases and outbreak of new infectious diseases. In view of this, it is important for medical students to equip themselves with sufficient knowledge and skills on public health.

With of a new era in information technology, e-learning defined as the use of internet technologies to deliver a wide array of solutions that enhance knowledge and performance, has become an important component of today's teaching and learning process in higher educational institutes[3], [4]. e-learning can be used as an active learning strategy which promotes self-directed learning [5]. Presently more and more educators are experimenting with this innovative learning approach to facilitate traditional teaching in a variety of university courses [4]-[8]. The findings suggested that e-learning was generally well accepted by the students as a

Manuscript received April 4, 2014; revised June 20, 2014. This work was supported by the grant under the European Union 7 Framework Program funded project 'Asian Regional Capacity Development Research on Social Determinants of Health' (project no: 0218513008).

The authors are with the Epidemiology and Statistics Department, Tongji Medical College, Huazhong University of Science and Technology, Hang Kong Road, Wuhan, China (e-mail: zhixia.qiqi@gmail.com, 14234712@qq.com, pengying718@foxmail.com, cherryaries@163.com, weirongy@gmail.com). supplement to traditional methods of teaching and has made an effective contribution to the improvement of learning outcomes [4]. Compared to conventional learning, e-learning has the advantage that participants can choose the place and time of education themselves.

Although many studies have shared their experiences on using e-learning to their traditional teaching, little literature explores the application of e-learning into public health education.

Based on the suggestion that e-learning can promote an active, deeper approach for learning that enhances student learning outcomes [2], we designed an e-learning platform in public health education. In addition, we also wanted to use the platform to effectively distribute some course materials. In order to assess the effectiveness of e-learning in public health education, we conducted a pilot study with social medicine among international medical students of the Bachelor of Medicine and Bachelor of Surgery (MBBS) in a medical college in China.

\section{MAterials AND Methods}

\section{A. Ethics Committee Approval}

This study has been ethically approved by the Institutional Review Board of Tongji Medical College, Huazhong University of Science and Technology.

\section{B. Study Design and Sample}

This study was a descriptive study, conducted at Tongji Medical College, Huazhong University of Science \& Technology, with a total of 87 international students of the Bachelor of Medicine and Bachelor of Surgery (MBBS) were enrolled in this study in spring semester, 2013. Course of social medicine was one of the compulsory subjects offered in this semester and had been traditionally taught via traditional lectures to these students. After all the students consented to take part in this project, they were encouraged to register in the e-learning course platform using the specified login name and password given by the researcher. They can access the social medicine course material present on classroom teaching and relevant exercises based on their own interests and needs.

\section{1) The platform for e-learning of social medicine}

The e-learning platform, based on Moodle system (Modular Object-oriented Dynamic Learning Environment), was established in 2012 and the complete web address of the platform is http://elearning.tjmu.edu.cn/moodle/. For easy access to the students, appropriate navigation keys were given on the home page of the platform. The platform has several functional modules. For example, the setting module and course module. The setting module enabled teachers to 
add new learning resources, arrange assignment flexibly and also enabled students to mater their learning process and learning effectiveness themselves.

There were two course modules: self-study course module and blended course module. The self-study course module included 5 courses. To enhance knowledge of the students and broaden their eyes, we invited some famous international professors to give lectures on public health, for example, lecture on descriptive epidemiology, in our university. All lectures were audio recorded (.swf format) and its corresponding lecture notes (in .pdf format) were uploaded onto the platform. Students were able to either download or view them online.

Courses in the blended course module were interactive courses. In this module, students were allowed to communication with fellow students and tutors through a discussion forum and an online chat room. The platform also allowed students to send personal messages to each other or to tutors for private discussion.

Besides, the platform has several user-friendly functions, such as bulletin board system, calendar, and useful links and so on. All of the students' online learning activity would be recorded by the attendance register in the platform, such as the time started to learn, the duration of his/her learning process, the "visit" times and so on. These records would help the teacher to supervising the study pace of the students.

\section{2) The social medicine course}

Social medicine course, one of essential courses in public health education, was offered in the pilot study in blended course module. The Social Medicine Course is presented in English and covers seven topics: Topic 1 - Medical mode and research method, Topic 2 - Social health status and health indicators1, Topic 3 - Social health status and health indicators2, Topic 4 - Culture and Health, Topic 5 - Behavior and health, Topic 6 - Measure quality of life and health risk appraisal, Topic 7 - Social health strategy. Each topic will take approximately fifteen to thirty minutes.

\section{Social Medicine}

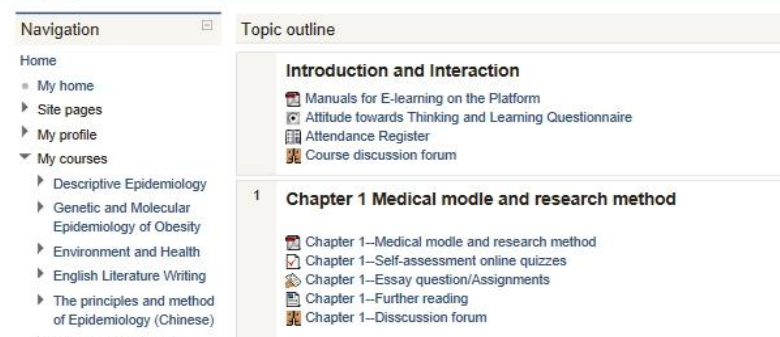

Fig. 1. Example of one topic in social medicine course.

Each topic is comprised of 4 sections (Fig. 1): learning resource materials, self-assessment online quizzes, assignments, further reading and discussion forum. Learning materials were saved in the PDF format and were available for download. Students can either choose to read the PDF online or download the PDF to study. To help learners to steer they during the learning and measure their knowledge of the topics, the self-assessment online quizzes were scheduled in each topic. The online quizzes are comprised of 4 single-choice questions and all these questions were linked to the key points of each topic. The quiz settings also allowed students to receive the correct answers, their marks, and feedback for the answers immediately after their each attempt. Each assignment required to write a short or long answer and to submit this to the tutor. Besides, several relevant books and articles were listed for further reading, so that a better understanding of each topic can be obtained. Furthermore, students were also encouraged to post any questions or inquiries on the discussion forum. Feedback on all assignments and the inquiries from the teachers were returned and displayed online, usually within one to two days.

\section{Evaluation Methods}

Questionnaire: For successful implementation of e-learning programme, computer and internet access to students is essential [5] and their attitudes toward e-learning should also be evaluated before the e-learning [9]. So a self-administrated questionnaire of computer literacy and attitudes towards e-learning was used. The questionnaire consisted of three parts. The first part provided demographic information (student ID, age, gender, country of residence); the second part enabled the participants to self-evaluate their computer- literacy, including access to the computer and internet, satisfaction with the speed of the internet, e-learning experiencing, self-rated computer skills; and the third part provided the participants' attitudes toward e-learning.

Online activity logs: Data regarding individual student's online activity logs were generated by the platform and were downloaded and analyzed offline using a Microsoft Excel worksheet. The online activity of students in social medicine course was calculated based on their total time duration, number of visits and performance in online quizzes. "Total time duration" refers to the total time that spent on line for learning of the course; "visits" refers to the total number of clicks that students perform for accessing the course contents; "performance in online quizzes" in the quizzes was based on the mean score obtained by the students. The maximum possible score of the online quizzes in each course topic was 100.

Final exam scores: The final examination scores were the testing scores of the social medicine course evaluation at the end of the semester. The students were requested to sit in the class to complete the final exam.

To evaluate value of the e-learning platform usage in improving student exam performance, correlations between online activity $\log s$ and the final examination marks were analyzed in social medicine course.

\section{Data Analysis}

Statistical Package for the Social Sciences (SPSS) software was used to analyze the data. Descriptive statistics such as percentage, mean, and standard deviation (SD) were used to describe the students' demographic data. Spearman's correlation test was used for all correlation assessments. An unpaired t-test was used to examine the gender difference of total time duration. The significant level was set at $\mathrm{p}<0.05$.

\section{RESUlTS}

\section{A. Demographic Characteristics}

In total, 87 students (52 females, 35 males; mean age, 
$22.11 \pm 1.595$ years) were recruited in the study and registered as platform users. Of the registered students, 51students (58.6\%) were from Africa, 31 students $(35.6 \%)$ were from Asia while 5 students $(5.6 \%)$ were from other countries.

\section{B. Computer-Literacy and Attitude towards e-Learning}

As shown in Table I, of the 87 students, $98.9 \%$ students could readily access to the computer and connect to the e-learning platform either by using their personal computer or the public computer; 58 students $(66.7 \%)$ were satisfied with the speed of the internet. Of the students, only 12 students $(13.8 \%)$ did not have e-learning experience and 2 students $(2.3 \%)$ were lack of basic computer using skills. When talking about the attitudes toward e-learning, 74 $(85.1 \%)$ students would like to attend the e-learning course if the university offers it for free.

\section{Total Time Duration}

TABLE I: COMPUTER-LITERACY AND ATTITUDE TOWARDS E-LEARNING

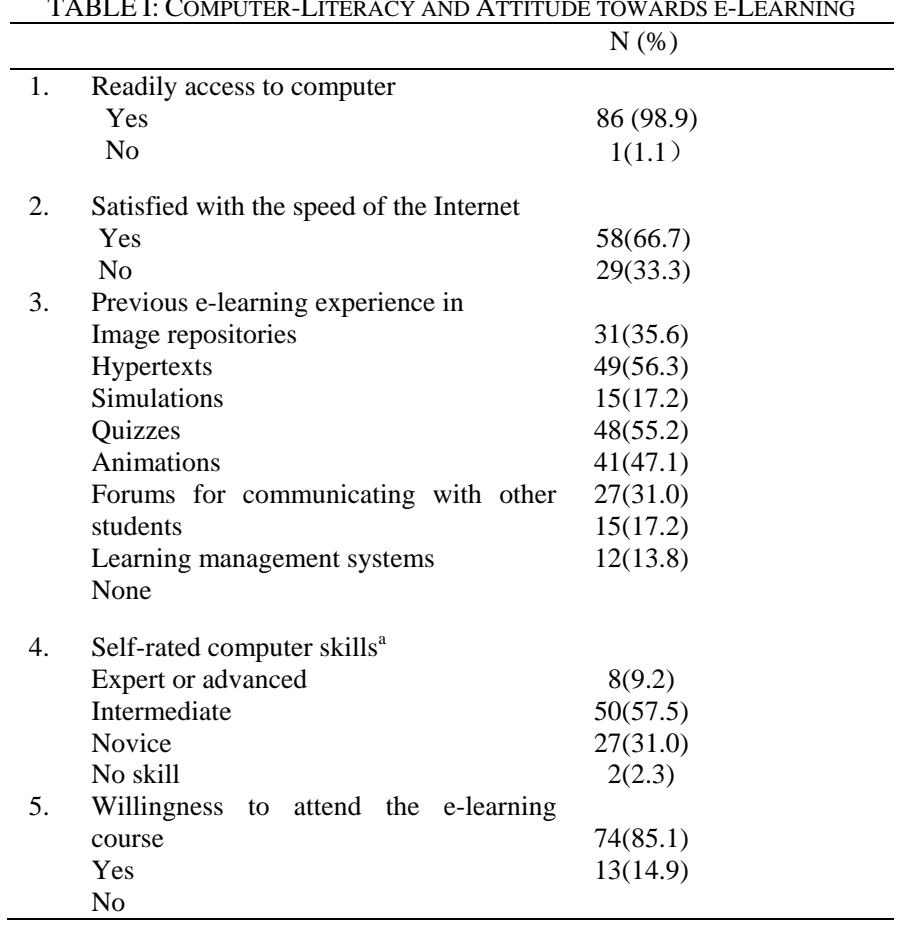

a :Self-rated computer skills were classified into 3 levels.

Expert or advanced refers to someone could be able to repair malfunctions related to hardware and software; Intermediate refers to someone could be able to use different software programs; Novice refers to someone could be able to do basic word processing and search the Internet.

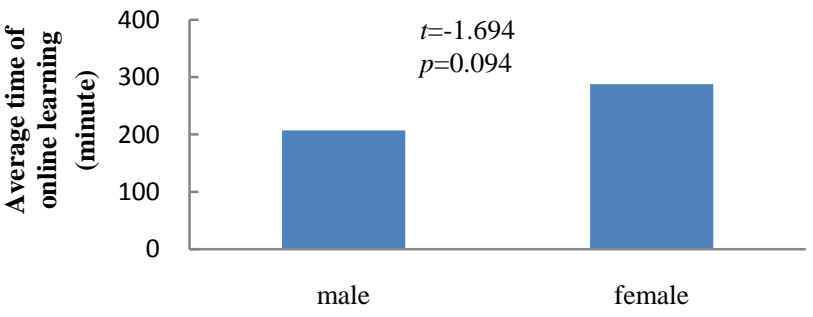

Fig. 2. The average time of online learning for male and female.

The average time duration of online learning for the study was 257 minutes and maximum of total time duration reached to 884 minutes. As shown in Fig. 2, average online learning time for the male and female was 207, 288 minutes respectively, and there was no significant difference between them $(t=-1.694, p=0.094)$.

\section{Examination Marks and Usage of e-Learning Platform}

When individual student exam marks were compared with the e-learning platform usage, there was significant correlation between student examination scores and total time duration (Fig. 3). As shown in Fig. 4, there was a positive correlation between students' performance in the online quizzes and their final exam marks ( $r s=0.416, p$ $<0.001$ ). A correlation between visit times ( $r s=0.457, p$ $<0.001)$ and the final examination scores was also found in this study (Fig. 5).

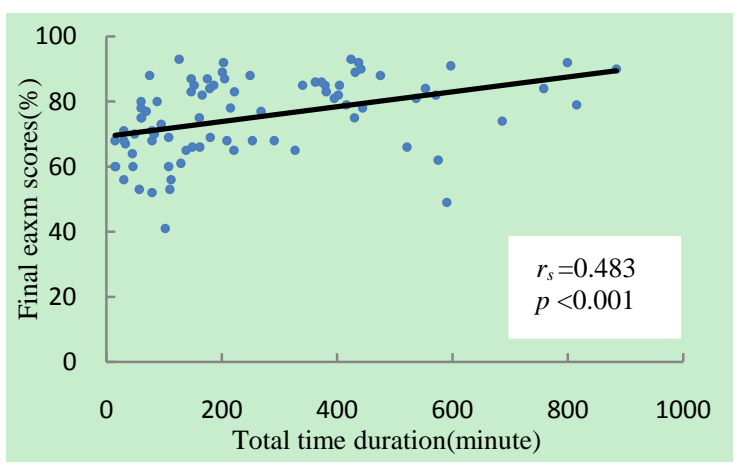

Fig. 3. Correlation between total time duration and the final exam scores.

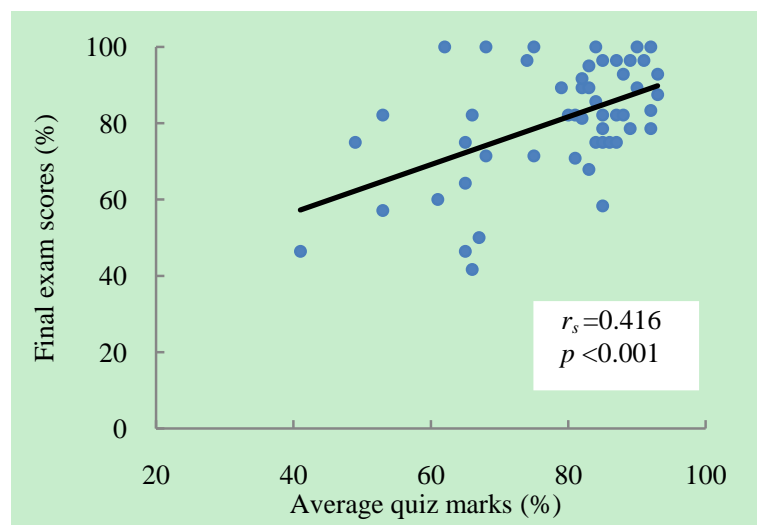

Fig. 4. Correlation between students' final scores and average online.

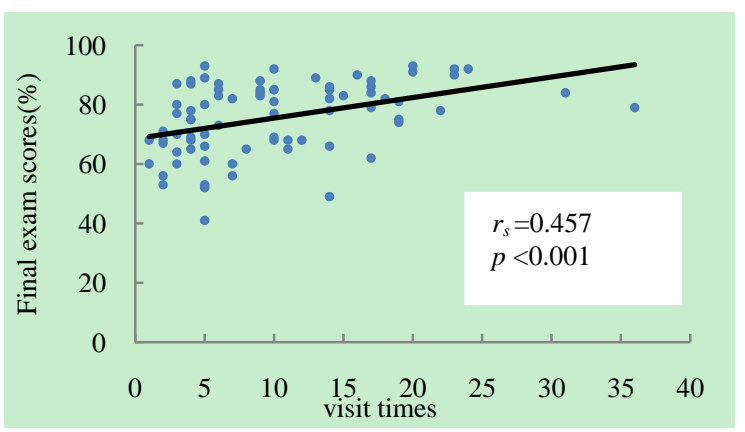

Fig. 5. Correlation between students' visit times and final exam scores.

\section{DissCussion}

The present study demonstrates an innovative way of integrating e-learning platform in teaching and learning in social medicine course among medical students. In this e-learning project, we assessed the effectiveness of this e-learning by evaluate the correlation between the e-learning platform usage and final exam performance. And it showed that there was a modest but significant correlation between them.

Access to computer and internet is essential to a successful implementation of e-learning programmes, and attitudes toward e-learning are also important in the implementation of 
e-learning project [5]. In this study, almost all registered students could readily access to the computer and internet either by using their personal computer or by the public computer, suggesting that most students could readily connect to the e-learning platform and complete the online learning. And most of them have positive attitudes towards e-learning.

In this study, the introduction of e-learning platform had a positive effect on improving students' final exam, suggesting that e-learning can be beneficial for students in various ways as a supplement approach to traditional teaching. The interactive features that promote self-directed learning can assist students to better master concepts being taught which resulting in better exam performance. Self-assessment online quizzes with instant feedback and assignment would allow them to better evaluate their understanding of the subject and facilitate exam preparation. Furthermore, the applying of complementary learning materials could increase their motivation to study.

In line with previous studies [2], [4], [10], we found that students' performance in online quizzes positively correlated with their performance in final exams. May be it is natural for good students to do well in online quizzes and subsequently perform better in exams. In addition, total time duration and visits time were also found positively correlated with student exam performance, which were consisted with the previous studies [11], [12]. However, the correlation between total time duration and student exam performance were not found in one previous study [4]. The inconsistent findings may be that students spend the time surfing the internet rather than learning. Therefore, it's essential to apply some software to calculate the specific online learning time of students.

\section{CONCLUSION}

In conclusion, the present study demonstrates the effectiveness of using e-learning as a supplemental to teaching in public health education. Based on our initial evaluation, the introduction of e-learning platform may improve students' learning outcomes. Overall, e-learning is promising and worthwhile for further application in public health education.

\section{CONTRIBUTORS}

Manage literature search: Z-XZ and YP; Data collection and data analysis: Z-XZ and YP; Revised the manuscript: W-RY, RH and PR; Wrote the first draft of the paper: Z-XZ.

\section{ACKNOWLEDENMENT}

The author thanks all the students who kindly participated in the study. The study was financially supported by a grant under the European Union 7 Framework Program funded project 'Asian Regional Capacity Development Research on Social Determinants of Health'.

\section{REFERENCES}

[1] Y. C. Tan, "Exploring teaching approach on public health," Modern Preventive Medicine, vol. 38, no. 20, pp. 4197-4201, 2011.

[2] A. M. Dantas and R. E. Kemm, "A blended approach to active learning in a physiology laboratory-based subject facilitated by an e-learning component," Adv Physiol Educ., vol. 32, no. 1, pp. 65-75, Mar. 2008.
[3] M. J. Rosenberg, E-Learning: Strategies for Delivering Knowledge in the Digital Age, New York: McGraw-Hill, 2001, p. 344.

[4] K. Seluakumaran et al., "Integrating an open-source course management system (Moodle) into the teaching of a first-year medical physiology course: a case study," Advances in Physiology Education, vol. 35, no. 4, pp. 369-377, Dec. 2011.

[5] N. Gaikwad and S. Tankhiwale, "Interactive e-learning module in pharmacology: a pilot project at a rural medical college in India," Perspectives on Medical Education, vol. 3, no. 1, pp. 15-30, Jan. 2013.

[6] K. Schilling, J. Wiecha, D. Polineni, and S. Khalil, "An interactive web-based curriculum on evidencebased medicine: design and effectiveness," Fam Med., vol. 38, no. 2, pp.126-132, Feb. 2006.

[7] M. Á. García Ureña et al., "Application of new technologies to the teaching of surgery in the school of medicine," Cirugía Española (English Edition), vol. 85, no. 3, pp. 165-170, Mar. 2009.

[8] M. M. Y. Tse and L. W. L. Lo, "A web-based e-learning course: integration of pathophysiology into pharmacology," Telemedicine and e-Health, vol. 14, no. 9, pp. 919-924, Nov. 2008.

[9] D. A. Cook, "A practical guide to developing effective web-based learning," Journal of general internal medicine, vol. 19, no. 6, pp. 698-707, Jun. 2004.

[10] J. Kibble, "Use of unsupervised online quizzes as formative assessment in a medical physiology course: effects of incentives on student participation and performance," Advances in Physiology Education, vol. 31, no. 3, pp. 253-260, Sep. 2007.

[11] J. Lovatt, O. E. Finlayson, and P. James, "Evaluation of studen engagement with two learning supports in the teaching of 1st year undergraduate chemistry," Chem. Educ. Res. Pract, vol. 8, no. 4, pp. 390-402, Sep. 2007

[12] C. Ramos and E. Yudko, “'Hits' (not 'Discussion Posts') predict student success in online courses: A double cross-validation study," Computers \& Education, vol. 50, no. 4, pp. 1174-1182, May 2008.

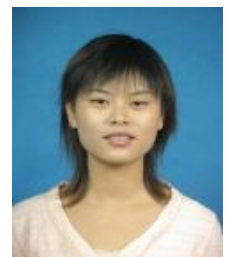

Zhang Zhixia was born in Shiyan city, Hubei province, China on November 9, 1983. In 2005, she got a bachelor's degree in nursing from Xianning Medical college in Xianning city, Hubei, China. In 2009, she got her master degree in nursing from Wuhan University in Wuhan, Hubei, China. Now she furthers her education on a third-year doctor program for public health in Tongji Medical College of Huazhong University of Science and Technology in Wuhan, Hubei, China. Before starting her doctor degree in Huazhong University of Science and Technology, she worked as a nursing teacher in Hubei University of Science and Technology from 2009 to 2013. Now, she acted as a research assistant in project "Asian Regional Capacity Development for Research on Social Determinants of Health", as well as in the project "Building grass-root health worker`s public health capacity through the Internet-based Interactive Training Platform".

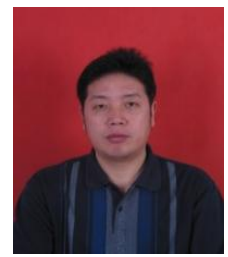

Ran Peng was born in Jingzhou city, Hubei province, China on October, 1968. In 1988, He got a bachelor`s degree in forensic medicine from Tongji Medical university of Huazhong University of Science and Technology in Wuhan, Hubei, China. His major study flied focus on social determinants of three factors of the disease research.

Now he works as a teacher in Tongji Medical College of Huazhong University of Science and Technology in Wuhan. Two of his main published articles are listed as follows: R. Y. Wei, S. Wei, H. J. Zhang, P. Ran, and Y. K. Zhou, "Necessity and difficulties of implementation of syndromic surveillance in China," Chin J Dis Cont rol Prev, vol. 11, no. 1, pp. 79-81, Feb 2007, etc..

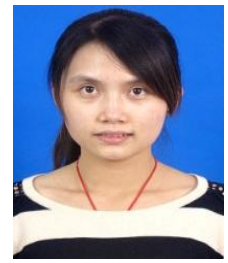

Peng Ying was born in Loudi city, Hunan province, China on August 17, 1987. In 2011, she got a bachelor's degree in nursing from Tongji Medical college of Huazhong University of Science and Technology in Wuhan, Hubei, China. Now she furthers her education on a third-year master program for public health in the same previous college.

Now she acted as a research assistant in project "Asian Regional Capacity Development for Research on Social Determinants of Health". Two of her main published articles are listed as follows: Y. Peng, Y. H. Wu, M. Zhu, H. J. Yu, S. F. Nie, and W. R. Yan, "Chinese urban-rural disparity in pandemic (H1N1) 2009 vaccination coverage rate and associated determinants: a cross-sectional telephone survey." Public Health, vol. 127, no. 10, pp. 930-937, Oct 2013, etc.. 


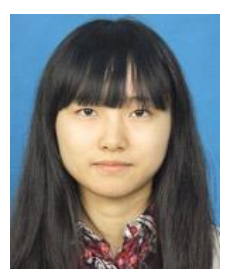

Hu Rong was born in Xianning City, Hubei Province, China on March 24, 1990. In 2013, she got a bachelor`s degree in nursing from Tongji Medical College of Huazhong University of Science and Technology in Wuhan, Hubei, China. Now, she furthers her education on a two-year master program for public health in the same previous college.

She mainly focuses on gene polymorphism in rennin-angiotensin system of pregnancy, and partly assists in the development and promotion of an internet-based training program for public health workers, as well as in the project "Asian Regional Capacity Development for Research on Social Determinants of Health".

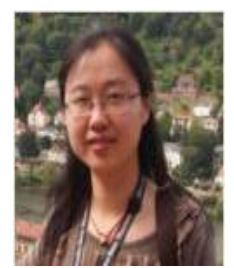

Yan Weirong was born in Yichang city, Hubei Province, China on February 21, 1976. In 2008, she got her doctoral degree in public health from Tongji Medical College of Huazhong University of Science and Technology in Wuhan, Hubei, China. From 2008-2010, she furthers her education on a two-year postdoctoral program for public health in Karolinska Institute, Sweden. Her major study flied focus on disease forecasting and early warning, social determinants of three factors of the disease, and molecular epidemiological study of chronic diseases.
She is a senior researcher in epidemiology and biostatistics in Huazhong University of Science and Technology. She has ten years of research experience in the field of Public Health, particularly in the research of health equity. She has been a main researcher on projects such as health services and management for TB patients in China, the relationship research between smoking and poverty in China, and developing integrated infectious diseases surveillance systems for early warning in poor areas. Three of her main published articles are listed as follows: R. W. Yan et al., "ISS-An Electronic Syndromic Surveillance System for Infectious Disease in Rural China," PLoS One, vol. 8, no. 4, p. e62749, Apr 2013, etc.. 